\title{
A Fuzzy Approach for Sensor Fault-Tolerant Control of wind energy conversion Systems
}

\author{
Elkhatib KAMAL ${ }^{1}$ Abdel AITOUCHE ${ }^{2}$ Mireille BAYART ${ }^{1}$ \\ ${ }^{1}$ LAGIS FRE CNRS 3033, Lille University,Nord, France e-mail: elkateb.kamal@gmail.com \\ ${ }^{2}$ LAGIS FRE CNRS 3033, Lille University,Nord, HEI, France e-mail: abdel.aitouche@hei.fr
}

\begin{abstract}
This paper presents the robust fuzzy fault tolerant control (FFTC) for nonlinear wind energy conversion systems (WECS) in the presence of bounded sensor faults and the state variable unavailable for measurement based on Takagi-Sugeno (TS) fuzzy model. Sufficient conditions are derived for robust stabilization in the sense of Lyapunov asymptotic stability and are formulated in the format of linear matrix inequalities (LMIs). The closed-loop system will follow those of a userdefined stable reference model in the presence of bounded sensor faults. The effectiveness of the proposed fuzzy fault tolerant controller and fuzzy observer design methodology is finally demonstrated through simulations on the WECS.
\end{abstract}

Keywords: Takagi-Sugeno observer; LMI; WECS; FTC; Fuzzy Proportional Integral Observer.

\section{Introduction}

Stability is one of the most important problems in the analysis and synthesis of control systems. Recently, the issue of stability of fuzzy control systems in nonlinear stability frameworks has been considered extensively [1], [2]. Ref. [2] presented a design method for the stabilization of a class of nonlinear systems as described by TS fuzzy model. In order to design a fuzzy controller, they used the concept of the so-called parallel distributed compensation (PDC) and linear matrix inequality (LMI). Ref. [3] also presented stability conditions satisfying decay rate for TS fuzzy model.

Since faults are frequently a source of instability and encountered in various engineering systems, the issue of a robust fuzzy controller design for faulty nonlinear systems has received considerable interest [4],[5]. Ref. [4] derived robust stability conditions for a fuzzy system with sensor faults. Ref. [5] also presented active fault-tolerant control for nonlinear systems with sensor faults and a method for designing robust controllers to stabilize sensor fault nonlinear systems.

More recently, in [6]-[8] the fault tolerant control strategy for wind energy conversion systems has been well developed and extensively applied to efficiently deal with the problems of robust stabilization and disturbance rejection.

This paper is dedicated to the design of a fuzzy fault tolerant control strategy for nonlinear systems with sensor faults described by TS models. This approach is an extension of the work proposed in [4], [5]. In designing a fuzzy FTC control system, the nonlinear systems are represented by TS fuzzy model with sensor faults. PDC is employed to design the fuzzy controllers from TS fuzzy model. A sufficient condition is derived so that the closed-loop system is asymptotically stable and will follow those of a user-defined stable reference model despite the presence of bounded sensor faults. Based on the derivation, we obtain sufficient conditions, expressed in LMI terms, for the existence of robust fuzzy controllers for TS fuzzy model with sensor faults. The state feedback gains of a robust fuzzy controller and the gains of the fuzzy observer can also be directly obtained from the LMI solutions.

This paper is organized as follows: Section 2 describes the fuzzy plant model, fuzzy observer and reference model. The Proposed FTC Fuzzy controller and the condition for stability are presented in section 3 . Section 4 presents description of WECS model and TS fuzzy description. In Section 5 simulation results illustrate the effectiveness of the proposed control method for wind systems. A conclusion is drawn in section 6 .

\section{TS fuzzy model, reference model and fuzzy ob- server}

\subsection{TS fuzzy plant model with sensor faults}

The TS fuzzy model is described by fuzzy IF-THEN rules, which represent local linear input-output relationships of nonlinear systems [9]. The ith rule of the TS fuzzy model with sensor fault is in the following form.

Plant Rule $i: q_{1}(t)$ is $N_{1}^{i}$ AND ... AND $q_{\psi}(t)$ is $N_{\psi}^{i}$ Then $\dot{x}(t)=\mathrm{A}_{\mathrm{i}} \mathrm{x}(\mathrm{t})+\mathrm{B}_{\mathrm{i}} \mathrm{U}(\mathrm{t})$,

$$
y(t)=C_{i} x(t)+\mathrm{E}_{\mathrm{i}} \mathrm{f}(\mathrm{t})
$$

where $N_{\Omega}^{i}$ is a fuzzy set of rule $i, \Omega=1,2, \ldots, \psi$, $i=1,2, \ldots, p, \quad \mathrm{x}(t) \in \kappa^{\mathrm{nx} 1}$ is the state vector, $\mathrm{U}(t) \in \kappa^{\mathrm{nx} 1}$ is the input vector, $\mathrm{y}(t) \in \kappa^{\mathrm{mx} 1}$ is the output vector, $\mathrm{f}(t) \in \kappa^{\mathrm{rx} 1}$ represents the fault which is assumed to be bounded, $A_{i} \in \kappa^{\mathrm{nxn}}$ and $B_{i} \in \kappa^{\mathrm{nxn}}, C_{i} \in \kappa^{\mathrm{gxn}}, \mathrm{E}_{\mathrm{i}}$ are system matrix, input matrix, output matrix and fault matrix, respectively, which are assumed to be known. It is supposed that the matrix $E_{i}$ is full column rank, i.e. $\operatorname{rank}\left(E_{i}\right)=r$. It is assumed that the derivative of $\mathrm{f}(\mathrm{t}) \mathrm{w}$. r.t to time is norm bounded, i.e. $\|\dot{\mathrm{f}}(t)\| \leq d_{1}$ and $0 \leq d_{1}<\infty, p$ is the number of IF-THEN rules, and $q_{1}(t), \ldots, q_{\psi}(t)$ are assumed measurable variables and do not depend on the sensor faults [10].

The defuzzified output of (2) subject to sensor faults is represented as follows [4]:

$$
\begin{aligned}
& \dot{x}(t)=\sum_{\mathrm{i}=1}^{\mathrm{p}} \mu_{i}(\mathrm{q}(\mathrm{t}))\left[A_{\mathrm{i}} \mathrm{x}(\mathrm{t})+B_{i} \mathrm{U}(\mathrm{t})\right], \\
& y(t)=\sum_{\mathrm{i}=1}^{\mathrm{p}} \mu_{i}(\mathrm{q}(\mathrm{t}))\left[C_{\mathrm{i}} \mathrm{x}(\mathrm{t})+\mathrm{E}_{\mathrm{i}} \mathrm{f}(\mathrm{t})\right]
\end{aligned}
$$


Where

$$
h_{i}(q(t))=\prod_{\alpha=1}^{\psi} N_{\alpha}^{i}(q(t)), \mu_{\mathrm{i}}(\mathrm{q}(\mathrm{t}))=\frac{h_{i}(q(t))}{\sum_{\substack{p \\ i=1}}^{p} h_{i}(q(t))}
$$

Some basic properties of

$$
0 \leq \mu_{i}(\mathrm{q}(\mathrm{t})) \leq 1, \quad \sum_{\mathrm{i}=1}^{\mathrm{p}} \mu_{i}(\mathrm{q}(\mathrm{t}))=1 \quad \forall \mathrm{i}=1,2, \ldots ., \mathrm{p}
$$

\subsection{Reference model}

A reference model is a stable linear system without faults given by [9],

$$
\begin{aligned}
& \dot{\bar{x}}(t)=\mathrm{A}_{\mathrm{r}} \overline{\mathrm{x}}(\mathrm{t})+\mathrm{B}_{\mathrm{r}} \mathrm{r}(\mathrm{t}) \\
& \bar{y}(t)=C_{r} \bar{x}(t)
\end{aligned}
$$

Where $\overline{\mathrm{x}}(t) \in \kappa^{\mathrm{nx} 1}$ is the state vector of reference model, $\mathrm{r}(t) \in \kappa^{\mathrm{nx} 1}$ is the bounded reference input, $A \in \kappa^{\mathrm{nxn}}$ is the constant stable system matrix, $B_{r} \in \kappa^{\mathrm{nxn}}$ is the constant input matrix, $C_{r} \in \kappa^{\mathrm{mxn}}$ is the constant output matrix. $\overline{\mathrm{y}}(t) \in \kappa^{\mathrm{mx} 1}$ is the reference output.

\subsection{Fuzzy Proportional Integral Observer (FPIO) design}

Definition 1: If the pairs $\left(A_{i}, C_{i}\right), i=1,2, \ldots, p$, are observable, the fuzzy system (1) is called locally observable[11].

For the fuzzy observer design, it is assumed that the fuzzy system (1) is locally observable. First, the local state observers are designed as follows, based on the triplets $\left(A_{i}, B_{i}, C_{i}\right)$. In order to detect and estimate faults, the following fault estimation fuzzy state observer for TS fuzzy model with sensor faults (1) is formulated as follows [4],[5]:

Observer Rule $i$ : IF $q_{I}(t)$ is $N_{1}^{i} \operatorname{AND} \ldots$ AND $q_{\psi}(t)$ is $N_{\psi}^{i}$

$$
\text { Then } \begin{aligned}
\dot{\hat{x}}(t) & =A_{i} \hat{\mathrm{x}}(\mathrm{t})+B_{i} \mathrm{u}(\mathrm{t})+\mathrm{K}_{i}(\mathrm{y}(\mathrm{t})-\hat{\mathrm{y}}(\mathrm{t})), \\
\dot{\hat{\mathrm{f}}}(\mathrm{t}) & =\mathrm{L}_{\mathrm{i}}(\mathrm{y}-\hat{\mathrm{y}})=\mathrm{L}_{\mathrm{i}} \tilde{\mathrm{y}} \\
\hat{y}(t) & =C_{i} \hat{x}(t)+\mathrm{E}_{\mathrm{i}} \hat{\mathrm{f}}(\mathrm{t}) \quad i=1,2, \ldots, p
\end{aligned}
$$

Where $K_{i}$ is the proportional observer gain for the ith observer rule and $L_{i}$ are their integral gains to be determined. $\hat{y}(t)$ is the final output of the fuzzy observer.

$\tilde{y}(t)$ is the estimation error. The defuzzified output of (5) subject to sensor faults is represented as follows:

$$
\begin{aligned}
& \dot{\hat{x}}(t)=\sum_{\mathrm{i}=1}^{\mathrm{p}} \mu_{i}(\mathrm{q}(\mathrm{t}))\left[A_{\mathrm{i}} \hat{\mathrm{x}}(\mathrm{t})+B_{i} \mathrm{U}(\mathrm{t})+\mathrm{K}_{\mathrm{i}} \tilde{\mathrm{y}}(\mathrm{t})\right] \\
& \dot{\hat{\mathrm{f}}}(\mathrm{t})=\sum_{i=1}^{p} \mu_{i} \mathrm{~L}_{\mathrm{i}} \tilde{\mathrm{y}} \\
& \hat{y}(t)=\sum_{\mathrm{i}=1}^{\mathrm{p}} \mu_{i}(\mathrm{q}(\mathrm{t}))\left[C_{\mathrm{i}} \hat{\mathrm{x}}(\mathrm{t})+\mathrm{E}_{\mathrm{i}} \hat{\mathrm{f}}(\mathrm{t})\right]
\end{aligned}
$$

\section{Proposed FFTC algorithm design}

In this section, we present LMI-based solutions to the fuzzy FTC controller synthesis problems for nonlinear systems with sensor faults described by the TS fuzzy model. The proposed fuzzy FTC controller can be designed such that the states of the closed-loop system will follow those of a user-defined stable reference model (1) despite the presence of sensor faults.

\subsection{PDC technique}

The concept of PDC in [2] is utilized to design fuzzy controllers to stabilize fuzzy system (2). The idea of PDC is to associate a compensator for each rule of the fuzzy model. The resulting overall fuzzy controller is a fuzzy blending of each individual linear controller. The fuzzy controller shares the same fuzzy sets with the fuzzy system (2).

\subsection{Proposed fuzzy controller}

Definition 2: If the pairs $\left(A_{i}, B_{i}\right), \mathrm{i}=1,2, \ldots, \mathrm{p}$, are controllable, the fuzzy system (1) is called locally controllable[11].

For the fuzzy controller design, it is assumed that the fuzzy system (1) is locally controllable. First, the local state feedback controllers are designed as follows, based on the pairs $\left(A_{i}, B_{i}\right)$. Using PDC the ith rule of the fuzzy controller which is the following format,

Controller Rule $i$ : $q_{1}(t)$ is $N^{i}{ }_{1}$ AND ... AND $q_{\psi}(t)$ is $N^{i}$

$$
\text { Then } u(t)=u_{i}(t)
$$

where $\mathrm{u}_{\mathrm{i}}(t) \in \kappa^{\mathrm{nx} 1}$ is the output of the ith rule controller that will be defined in the next sub-section. The global output of the fuzzy controller is given by

$$
U(t)=\sum_{\mathrm{i}=1}^{\mathrm{p}} \mu_{i}(\mathrm{q}(\mathrm{t})) u_{i}(\mathrm{t})
$$

\subsection{Design of the proposed FFTC controller}

We design the control law $u_{i}(t)$ for $i=1,2, \ldots, p$, such that closed-loop system behaves like the stable reference model. From (2), (3) and (8), writing $\mu_{i}(\mathrm{q}(\mathrm{t}))$ as $\mu_{i}$, we have,

$$
\begin{aligned}
& \dot{x}(t)=\sum_{\mathrm{i}=1}^{\mathrm{p}} \mu_{i}\left[A_{i} \mathrm{x}(\mathrm{t})+B_{i} u_{i}(\mathrm{t})\right] \\
& y(t)=\sum_{\mathrm{i}=1}^{\mathrm{p}} \mu_{i}\left[C_{i} \mathrm{x}(\mathrm{t})+\mathrm{E}_{\mathrm{i}} \mathrm{f}(\mathrm{t})\right]
\end{aligned}
$$

we use the property

$$
\sum_{i=1}^{p} \mu_{i}=\sum_{\mathrm{i}=1}^{\mathrm{p}} \sum_{\mathrm{j}=1}^{\mathrm{p}} \mu_{\mathrm{i}} \mu_{j}=1, B=\sum_{\mathrm{i}=1}^{\mathrm{p}} \mu_{i} B_{i}, E=\sum_{\mathrm{i}=1}^{\mathrm{p}} \mu_{i} E_{i}
$$

Note that $B$ and $E$ are known. Also from (3), (4) and (8), we have

$$
\begin{aligned}
& \dot{\hat{x}}(t)=\sum_{\mathrm{i}=1}^{\mathrm{p}} \mu_{i}(\mathrm{q}(\mathrm{t}))\left[A_{i} \hat{\mathrm{x}}(\mathrm{t})+B_{i} u_{i}(\mathrm{t})+\mathrm{K}_{\mathrm{i}} \tilde{\mathrm{y}}(\mathrm{t})\right] \\
& \hat{y}(t)=\sum_{\mathrm{i}=1}^{\mathrm{p}} \mu_{i}(\mathrm{q}(\mathrm{t}))\left[C_{i} \hat{\mathrm{x}}(\mathrm{t})+\mathrm{E}_{\mathrm{i}} \hat{\mathrm{f}}(\mathrm{t})\right] \\
& \text { let } \quad e_{1}(t)=x(t)-\bar{x}(t) \\
& \mathrm{e}_{2}(\mathrm{t})=\mathrm{x}(\mathrm{t})-\hat{\mathrm{x}}(\mathrm{t}), \quad \tilde{\mathrm{f}}(\mathrm{t})=\mathrm{f}(\mathrm{t})-\hat{\mathrm{f}}(\mathrm{t})
\end{aligned}
$$


The dynamics of $\mathrm{e}_{1}(\mathrm{t})$ is given by $\dot{\mathrm{e}}_{1}(\mathrm{t})=\dot{\mathrm{x}}(\mathrm{t})-\dot{\mathrm{x}}(\mathrm{t})$ $\dot{\mathrm{e}}_{1}(\mathrm{t})=\sum_{\mathrm{i}=1}^{\mathrm{p}} \mu_{i}\left[\mathrm{~A}_{\mathrm{i}} \mathrm{x}(\mathrm{t})+B_{i} u_{i}(\mathrm{t})-\mathrm{A}_{\mathrm{r}} \overline{\mathrm{x}}(\mathrm{t})-\mathrm{B}_{\mathrm{r}} \mathrm{r}(\mathrm{t})\right]$

The dynamics of $\mathrm{e}_{2}(\mathrm{t})$ is expressed as follow:

$$
\dot{e}_{2}(t)=\sum_{i=1}^{p} \mu_{i}\left[\left(\mathrm{~A}_{\mathrm{i}}-\mathrm{K}_{\mathrm{i}} \mathrm{C}_{\mathrm{i}}\right) \mathrm{e}_{2}(\mathrm{t})-\mathrm{K}_{\mathrm{i}} \mathrm{E}_{\mathrm{i}} \tilde{\mathrm{f}}(\mathrm{t})\right]
$$

The dynamics of the fault error estimation can be written $\dot{\tilde{\mathrm{f}}}(\mathrm{t})=\dot{\mathrm{f}}(\mathrm{t})-\dot{\hat{\mathrm{f}}}(\mathrm{t})$. The assumption that the fault signal is constant over the time is restrictive, but in many practical situations where the faults are time-varying signals. So, we consider time-varying faults rather than constants faults; then the derivative of $\tilde{\mathrm{f}}(\mathrm{t})$ w.r.t time is

$$
\dot{\tilde{\mathrm{f}}}(\mathrm{t})=\dot{\mathrm{f}}(\mathrm{t})-\dot{\hat{\mathrm{f}}}(\mathrm{t})=\dot{\mathrm{f}}(\mathrm{t})-\sum_{i=1}^{p} \mu_{i}\left[\mathrm{~L}_{\mathrm{i}} \mathrm{C}_{\mathrm{i}} \mathrm{e}_{2}(\mathrm{t})+\mathrm{L}_{\mathrm{i}} \mathrm{E}_{\mathrm{i}} \tilde{\mathrm{f}}(\mathrm{t})\right]
$$

From (15) and (16), one can obtain:

$$
\dot{\phi}=\mathrm{A}_{o} \phi+B \underset{o}{\mathrm{f}}(\mathrm{t})
$$

With $\phi=\left[\begin{array}{c}e_{2}(t) \\ \tilde{\mathrm{f}}(\mathrm{t})\end{array}\right], \quad B_{o}=\left[\begin{array}{l}0 \\ \mathrm{I}\end{array}\right], A_{o}=\sum_{i=1}^{p} \mu_{i} A_{o i}$

Where $\mathrm{A}_{\mathrm{oi}}=\left[\begin{array}{ll}A_{i}-K_{i} C_{i} & -K_{i} E_{i} \\ -L_{i} C_{i} & -L_{i} E_{i}\end{array}\right]$

Consider the Lyapunov function candidate

$$
V\left(e_{1}(t), \phi(t)\right)=\frac{1}{2} e_{1}(\mathrm{t})^{\mathrm{T}} \mathrm{P}_{1} e_{1}(\mathrm{t})+\phi(\mathrm{t}){ }^{\mathrm{T}} \mathrm{P}_{2} \phi(\mathrm{t})
$$

Where $P_{1}$ and $P_{2}$ are time-invariant, symmetric and positive definite matrices. Let

$$
V_{1}\left(e_{1}(t)\right)=\frac{1}{2} e_{1}(\mathrm{t})^{\mathrm{T}} \mathrm{P}_{1} e_{1}(\mathrm{t}), V_{2}(\phi(t))=\phi(\mathrm{t})^{\mathrm{T}} \mathrm{P}_{2} \phi(\mathrm{t})
$$

The time derivative of $V_{1}\left(e_{1}(t)\right)$ is

$$
\begin{gathered}
\dot{V}_{1}=\frac{1}{2}\left\{\sum_{\mathrm{i}=1}^{\mathrm{p}} \mu_{i}\left[\mathrm{~A}_{\mathrm{i}} \mathrm{x}(\mathrm{t})+B_{i} u_{i}(\mathrm{t})-\mathrm{A}_{\mathrm{r}} \overline{\mathrm{x}}(\mathrm{t})-\mathrm{B}_{\mathrm{r}} \mathrm{r}(\mathrm{t})\right]\right\}^{\mathrm{T}} \\
\times \mathrm{P}_{1} e_{1}(\mathrm{t})+\frac{1}{2} e_{1}(\mathrm{t})^{\mathrm{T}} \mathrm{P}_{1}\left\{\sum _ { \mathrm { i } = 1 } ^ { \mathrm { p } } \mu _ { i } \left[\mathrm{~A}_{\mathrm{i}} \mathrm{x}(\mathrm{t})+B_{i} u_{i}(\mathrm{t})\right.\right. \\
\left.\left.-\mathrm{A}_{\mathrm{r}} \overline{\mathrm{x}}(\mathrm{t})-\mathrm{B}_{\mathrm{r}} \mathrm{r}(\mathrm{t})\right]\right\}
\end{gathered}
$$

We design $u_{i}(t), i=1,2, \ldots, p$ as follows,

- When $B$ is an invertible square matrix, the control law is given by

$$
u_{i}(t)=Z^{-1} Z_{u i}
$$

- When $B$ is not a square matrix, the control law is given by

$$
u_{i}(t)=B^{T} Z^{-1} Z_{u i}
$$

where $Z_{u i}=\left\{\left[\operatorname{He}_{1}(\mathrm{t})+\mathrm{A}_{\mathrm{r}} \overline{\mathrm{x}}(\mathrm{t})+\mathrm{B}_{\mathrm{r}} \mathrm{r}(\mathrm{t})-\mathrm{A}_{\mathrm{i}} \mathrm{x}(\mathrm{t})\right.\right.$

$$
\left.-0.5 \mathrm{e}_{1}(t)\|\hat{\mathrm{f}}(\mathrm{t})\| S_{\mathrm{E}}\left\|_{\max }\right\| \hat{\mathrm{f}}(\mathrm{t}) \| / \mathrm{e}_{1}(t)^{T} P_{1} \mathrm{e}_{1}(t)+\mathrm{S} \hat{\mathrm{f}}(\mathrm{t})\right\}
$$

Where $Z=B$ if $B$ is an invertible square matrix or $Z=B B^{T}$ if $B$ is not a square matrix, $\|\cdot\|$ denotes the $l_{2}$ norm for vectors and $l_{2}$ induced norm for matrices,
$\left\|S_{\mathrm{E}}\right\| \leq\left\|S_{\mathrm{E}}\right\|_{\max }, H \in \kappa^{\mathrm{nxn}}$ is a stable matrix to be designed. A block diagram of the closed-loop system is shown in Fig.1. It is assumed that $Z^{l}$ exists ( $Z$ is nonsingular). From (21) to (23) and assuming that $e_{1}(\mathrm{t}) \neq 0$ and choosing $\mathrm{S}$ so that $\mathrm{S}=\mathrm{E}$ and $S_{\mathrm{E}}=S^{T} S$, we obtain

$$
\begin{aligned}
& \dot{V}_{1}=\frac{1}{2} e_{1}(\mathrm{t})^{\mathrm{T}}\left(\mathrm{H}^{\mathrm{T}} \mathrm{P}_{1}+\mathrm{P}_{1} H\right) e_{1}(\mathrm{t}) \\
& +\frac{1}{2} \sum_{i=1}^{p} \mu_{i}\left[\hat{\mathrm{f}}(\mathrm{t})^{\mathrm{T}} S^{T} \mathrm{P}_{1} \mathrm{e}_{1}(\mathrm{t})+\mathrm{e}_{1}(\mathrm{t})^{\mathrm{T}} \mathrm{P}_{1} S \hat{\mathrm{f}}(\mathrm{t})-\|\hat{\mathrm{f}}(\mathrm{t})\| S_{\mathrm{E}}\left\|_{\max }\right\| \hat{\mathrm{f}}(\mathrm{t}) \|\right]
\end{aligned}
$$

Lemma1 [12]: Given constant matrices $W$ and $O$ appropriate dimensions for $\forall \varepsilon>0$, the following inequality holds:

$$
\mathrm{W}^{\mathrm{T}} \mathrm{O}+O^{T} W \leq \varepsilon W^{T} W+\frac{1}{\varepsilon} O^{T} O
$$

Using Lemma 1 to $\hat{\mathrm{f}}(\mathrm{t})^{\mathrm{T}} S^{T} \mathrm{P}_{1} \mathrm{e}_{1}(\mathrm{t})+e_{1}(\mathrm{t})^{\mathrm{T}} \mathrm{P}_{1} S \hat{\mathrm{f}}(\mathrm{t})$ yields

$$
\begin{aligned}
\dot{V}_{1}=\frac{1}{2} e_{1}(\mathrm{t})^{\mathrm{T}}\left(\mathrm{H}^{\mathrm{T}} \mathrm{P}_{1}+\mathrm{P}_{1} H+\mathrm{P}_{1} \mathrm{P}_{1}\right) e_{1}(\mathrm{t}) \\
+\frac{1}{2}\|\hat{\mathrm{f}}(\mathrm{t})\|\left(\left\|S_{\mathrm{E}}\right\|-\left\|S_{\mathrm{E}}\right\|_{\max }\right)\|\hat{\mathrm{f}}(\mathrm{t})\|
\end{aligned}
$$

The time derivative of $V_{2}(\phi(t))$ is

$$
\dot{V}_{2}(\phi(t))=\dot{\phi}(\mathrm{t})^{\mathrm{T}} \mathrm{P}_{2} \phi(\mathrm{t})+\phi(\mathrm{t})^{\mathrm{T}} \mathrm{P}_{2} \dot{\phi}(\mathrm{t})
$$

By substituting (17) into (26) and using Lemma 1 and the definition [10], one obtains

$$
\begin{aligned}
\dot{V}_{2}(\phi(t))=\sum_{i=1}^{p} \mu_{i} \phi(\mathrm{t})^{\mathrm{T}}\left(A_{o i}{ }^{T}\right. & \left.\mathrm{P}_{2}+\mathrm{P}_{2} A_{o i}+\mathrm{P}_{2} \mathrm{P}_{2}\right) \phi(\mathrm{t}) \\
& +\mathrm{f}_{1}^{2} \lambda_{\max }\left(B_{o}^{\mathrm{T}} B_{o}\right)
\end{aligned}
$$

Where $\lambda_{\max }($.$) denotes the largest eigen value.$

Combining (25) with (27), the time derivative of $V$ can be expressed as

$$
\begin{aligned}
\dot{V}\left(e_{1}(t), \phi(t)\right) \leq-\frac{1}{2} & e_{1}(\mathrm{t})^{\mathrm{T}} Q_{1} e_{1}(\mathrm{t})-\phi(\mathrm{t})^{\mathrm{T}} Q_{2} \phi(\mathrm{t}) \\
& +0.5\|\hat{\mathrm{f}}(\mathrm{t})\|\left(\left\|S_{\mathrm{E}}\right\|-\left\|S_{\mathrm{E}}\right\|_{\max }\right)\|\hat{\mathrm{f}}(\mathrm{t})\|
\end{aligned}
$$

Where $\mathrm{Q}_{1}=-\left(\mathrm{H}^{\mathrm{T}} \mathrm{P}_{1}+\mathrm{P}_{1} \mathrm{H}+\mathrm{P}_{1} \mathrm{P}_{1}\right)$, $Q_{2}=-\left(A_{o i}{ }^{T} \mathrm{P}_{2}+\mathrm{P}_{2} A_{o i}+\mathrm{P}_{2} \mathrm{P}_{2}+\delta\right)$ are a symmetric positive definite matrix, where $\delta=\mathrm{f}_{1}^{2} \lambda \max \left(B_{o}^{\mathrm{T}} B_{o}\right)$. From (28), we have

$$
\dot{V}\left(e_{1}(t), \phi(t)\right) \leq-\frac{1}{2} e_{1}(\mathrm{t})^{\mathrm{T}} Q_{1} e_{1}(\mathrm{t})-\phi(\mathrm{t})^{\mathrm{T}} Q_{2} \phi(\mathrm{t})
$$

$e_{1}$ and $\phi$ converges to zero if $\dot{V}<0 . \dot{V}<0$ if there exists a common positive definite matrix $P_{1}$ and $P_{2}$ such that

$$
\begin{aligned}
& \mathrm{H}^{\mathrm{T}} \mathrm{P}_{1}+\mathrm{P}_{1} \mathrm{H}+\mathrm{P}_{1} \mathrm{P}_{1}<0 \\
& A_{o i}{ }^{T} \mathrm{P}_{2}+\mathrm{P}_{2} A_{o i}+\mathrm{P}_{2} \mathrm{P}_{2}<-\delta I \quad i=1,2, \ldots, p
\end{aligned}
$$

From (29) and (30)

$$
\dot{V} \leq-\frac{1}{2} e_{1}(\mathrm{t})^{\mathrm{T}} Q_{1} e_{1}(\mathrm{t})-\phi(\mathrm{t})^{\mathrm{T}} Q_{2} \phi(\mathrm{t}) \leq 0
$$

If the time derivative of (18) is negative uniformly for all $e_{1}(t), \phi(t)$ and for all $t \geq 0$ except at 
$e_{1}(t)=0, \phi(t)=0$ then the controlled fuzzy system (9) is asymptotically stable about its zero equilibrium.

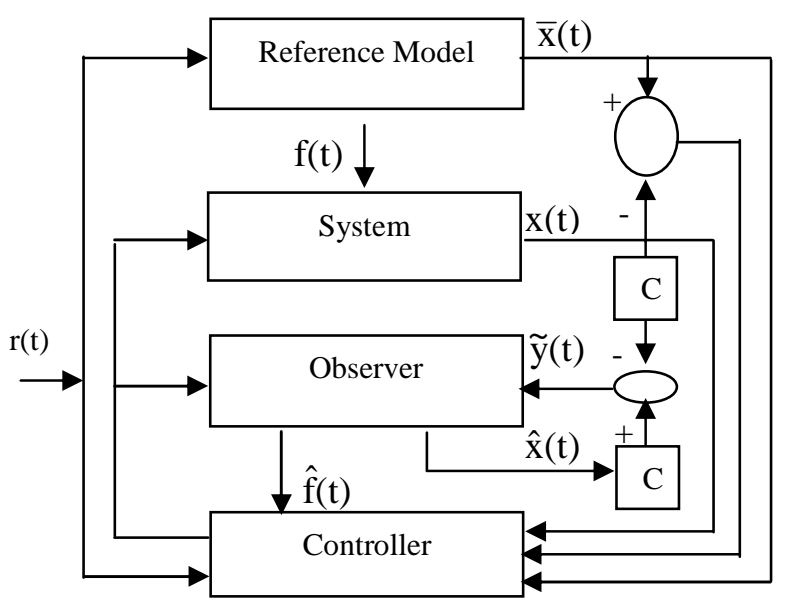

Fig. 1: Block diagram of FTC scheme

The results of this section can be summarized by the following lemma and theorem.

Lemma 2: The fuzzy control system of (9) subject to plant sensors faults is guaranteed to be asymptotically stable, and its states will follow those of a stable reference model of (4), if the following two conditions satisfy;

- $Z$ is nonsingular. One sufficient condition to guarantee the nonsingularity of $Z$ is that there exists $P$ such that,

$\mathrm{Z}_{\mathrm{i}}^{\mathrm{T}} \mathrm{P}+\mathrm{P} \mathrm{z}_{i}<0 \quad \forall i$

- The control laws of fuzzy controller of (8) are designed as (21) and (22)

Theorem: If there exist symmetric and positive definite matrices $P_{1}, P_{2}$, some matrices $K_{i}$ and $L_{i}$, and matrices $X_{i}, Y_{i}$, such that the following LMIs are satisfied, then the TS fuzzy system (14) and (17) describing the evolution of the errors $e_{1}(t), e_{2}(t)$ and, is asymptotically stabilizable via the TS fuzzy model based output- feedback controller (8), (22) and (23)

$$
\begin{aligned}
& \mathrm{H}^{\mathrm{T}} \mathrm{P}_{1}+\mathrm{P}_{1} \mathrm{H}+\mathrm{P}_{1} \mathrm{P}_{1}<0 \\
& A_{o i}{ }^{T} \mathrm{P}_{2}+\mathrm{P}_{2} A_{o i}+\mathrm{P}_{2} \mathrm{P}_{2}<-\delta I \quad i=1,2, \ldots, p
\end{aligned}
$$

According to the theorem, the most important step in designing the fuzzy observer based fuzzy controller is the solution of (33) for a common $P_{2}=P_{2}{ }^{T}$, a suitable set of observer gains $K_{i}$ and $L_{i}(i=1,2, \ldots, p)$. Equation (33) forms a set of bilinear matrix inequalities (BMI's). The BMI in (33) should be transformed into pure LMI as follows: For the convenience of design, assume $P_{2}=\operatorname{diag}\left(P_{11}, P_{22}\right)$. By multiplying (33) from left and right by $M_{11}=P_{11}^{-1}$ and apply the change of variables $Y_{i}=-P_{11} K_{i}$ and $X_{i}=-P_{22} L_{i}$, one obtain the following LMIs.

$$
A_{i}^{T} \mathrm{P}_{11}+\mathrm{P}_{11} A_{i}-\left(Y_{i} C_{i}\right)^{T}-Y_{i} C_{i}+\mathrm{P}_{11} \mathrm{P}_{11}<-\delta I
$$

$$
\left(\mathrm{X}_{\mathrm{i}} E\right)^{T}+\mathrm{X}_{\mathrm{i}} E+P_{22} P_{22}<-\delta I
$$

The inequalities in (34) and (35) are linear matrix inequality feasibility problems (LMIP's) in $P_{11}, P_{22}, Y_{i}$ and $X_{i}$. By solving (34) and (35) the observer gain $\left(K_{i}\right.$ and $L_{i}$ ) can be easily determined.

\section{System model and TS fuzzy description}

The underlying hybrid wind-diesel system is illustrated in Fig. 2. The hybrid generation system is composed of a wind-turbine coupled with a synchronous generator, a diesel-induction generator, and an energy storage system. In the given system, the wind turbine drives the synchronous generator that operates in parallel with the storage battery system. When the windgenerator alone provides sufficient power for the load, the diesel engine is disconnected from the induction generator. The PEI connecting the load to the main bus is used to fit the frequency of the power supplying the load as well as the voltage.

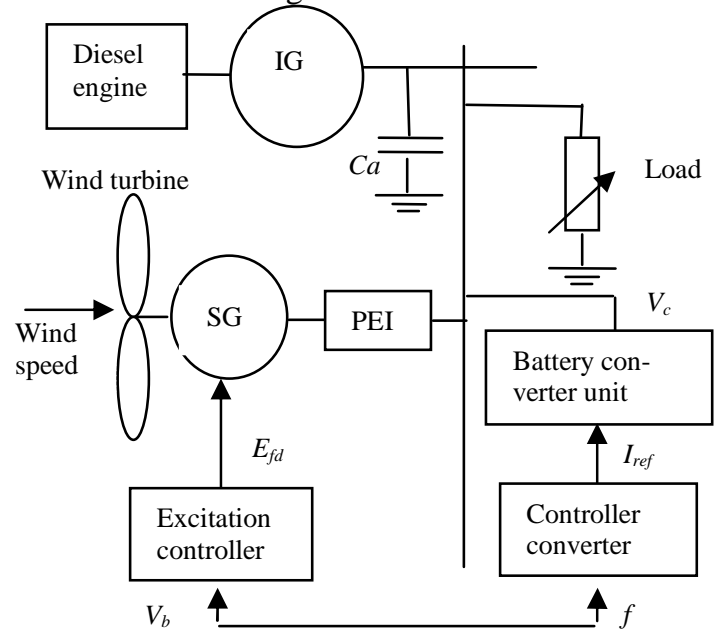

Fig.2:Structural diagram of hybrid wind-diesel storage system

The dynamics of the system can be characterized by the following equations [13]:

$$
\dot{x}=A(x) x(t)+B(x) u(t), \quad y=C x(t),
$$

where $\quad x(\mathrm{t})=\left[\begin{array}{ll}\mathrm{V}_{\mathrm{b}} & \omega_{\mathrm{s}}\end{array}\right]^{\mathrm{T}}, u(\mathrm{t})=\left[\begin{array}{ll}\mathrm{E}_{\mathrm{fd}} & I_{\mathrm{ref}}\end{array}\right]^{\mathrm{T}}$

$A=\left[\begin{array}{ll}1 & 1 \\ 0 & 1\end{array}\right]\left[\begin{array}{ll}\frac{L_{f}}{\tau \omega_{s} L_{m d}} & \frac{L_{f}}{\tau \omega_{s} L_{m d}}\left(L_{d} i_{s d}-\frac{r_{a} i_{s q}}{\omega_{s}}\right. \\ \frac{P_{\text {ind }}-P_{\text {load }}}{J_{s} \omega_{s} V_{b}} & -\frac{D_{s}}{J_{s}}\end{array}\right]$

$B=\left[\begin{array}{cc}1 & -V_{c} / J_{s} \omega_{s} \\ 0 & -V_{c} / J_{s} \omega_{s}\end{array}\right], \mathrm{C}=\left[\begin{array}{ll}1 & 0 \\ 0 & 1\end{array}\right]$

where $V_{c}$ is the AC side line-to-line voltage, $E_{f d}$ is the SG field voltage, $\omega_{\mathrm{s}}$ is the bus frequency (or angular speed of SG) $J_{s}, D_{s}$ are the inertia and frictional damping of SG, $i_{s d}, i_{s q}$ are the direct and quadrature current component of SG, $L_{d}, L_{f}$ are the stator $d$-axis and rotor inductance of $\mathrm{SG}, L_{m d}$ is the $d$-axis field mutual inductance, $\tau$ is the transient open circuit time constant, $r_{a}$ is the rotor resistance of SG, $P_{\text {ind }}$ is the power of the induction generator, $P_{\text {load }}$ is the power of the load, $I_{\text {ref }}$ is the direct current set point, and $V_{b}$ is the bus voltage. The control inputs are the excitation field voltage $\left(E_{f d}\right)$ 
of the SG and the direct-current set point $\left(I_{r e f}\right)$ of the converter. Equation (36) indicates that the matrices $A$ and $B$ are not fixed, but change as functions of state variables, thus making the model nonlinear. The used system parameters are shown in Table 1 [13], [14].

Table 1: System parameters

\begin{tabular}{|l|r|}
\hline Rated power & $1[\mathrm{MW}]$ \\
\hline Blade radius & $37.38[\mathrm{~m}]$ \\
\hline Air density & $0.55\left[\mathrm{~kg} / \mathrm{m}^{3}\right]$ \\
\hline Rated wind speed & $12.35[\mathrm{~m} / \mathrm{s}]$ \\
\hline Rated line ac voltage & $230[\mathrm{~V}]$ \\
\hline AC rated current & $138[\mathrm{~A}]$ \\
\hline DC rated current & $239[\mathrm{~A}]$ \\
\hline Rated Load power & $40[\mathrm{~kW}]$ \\
\hline The inertia of SG & $1.11\left[\mathrm{~kg} \mathrm{~m}{ }^{2}\right]$ \\
\hline Rated power of IG & $55[\mathrm{~kW}]$ \\
\hline The inertia of the IG & $1.40\left[\mathrm{~kg} \mathrm{~m}{ }^{2}\right]$ \\
\hline Torsional damping & $0.557[\mathrm{Nm} / \mathrm{rad}]$ \\
\hline Rotor resistance of SG & $0.96[\Omega]$ \\
\hline Stator d-axis inductance of SG & $2.03[\mathrm{mH}]$ \\
\hline Rotor inductance of SG & $2.07[\mathrm{mH}]$ \\
\hline d-axis field mutual inductance & $1.704[\mathrm{mH}]$ \\
\hline Transient open circuit time constant & $2.16[\mathrm{~ms}]$ \\
\hline
\end{tabular}

To design the fuzzy controller and the fuzzy observer, we must have a fuzzy model that represents the dynamics of the WECS. Therefore, we first represent the system with a TS fuzzy model. The system (36) is described by a TS fuzzy representation with the angular speed of SG $\omega_{s}$ and is the bus voltage $V_{b}$ as the premise variables and do not depend on the sensor faults [10]. Where $q_{1}(t)=1 / \omega_{s}, q_{2}(t)=1 / 1 \omega_{s} V_{b}$ are nonlinear terms. Then, we have

$$
\begin{gathered}
A=\left[\begin{array}{ll}
1 & 1 \\
0 & 1
\end{array}\right]\left[\begin{array}{ll}
\frac{L_{f}}{\tau L_{m d}} q_{1}(t) & \frac{L_{f}}{\tau \omega_{s} L_{m d}} q_{1}(t)\left(L_{d} i_{s d}-r_{a_{i} i_{s}} q_{1}(t)\right) \\
\frac{P_{\text {ind }}-P_{\text {load }}}{J_{s}} q_{2}(t) & -\frac{D_{s}}{J_{s}}
\end{array}\right] \\
B=\left[\begin{array}{cc}
1 & -V_{c} q_{1}(t) / J_{s} \\
0 & -V_{c} q_{1}(t) / J_{s}
\end{array}\right]
\end{gathered}
$$

Next, calculate the minimum and maximum values of $q_{1}(t)$ and $q_{2}(t)$ under $q_{1 \min } \leq q_{1}(t) \leq q_{1 \max }, q_{2 \min } \leq q_{2}(t) \leq$ $q_{2 \max }$. From the maximum and minimum values $q_{1}(t)$ and $q_{2}(t)$, can obtain the sector nonlinearity as follow,

$$
\begin{aligned}
& q_{1}(t)=q_{1 \max } N_{l}\left(q_{1}(t)\right)+q_{1 \min } N_{2}\left(q_{1}(t)\right) \\
& q_{2}(t)=q_{2 \max } M_{1}\left(q_{2}(t)\right)+q_{2 \min } M_{2}\left(q_{2}(t)\right)
\end{aligned}
$$

where $\quad N_{l}\left(q_{1}(t)\right)+N_{2}\left(q_{1}(t)\right)=1, \quad M_{1}\left(q_{2}(t)\right)+M_{2}\left(q_{2}(t)\right)=1$, $N_{l}{ }^{i}$ and $M_{l}{ }^{i}$ are a fuzzy term of rule $i$. The degree of membership function for $q_{1}(t)$ and $q_{2}(t)$ are depicted in Fig.3. Then, the nonlinear WECS system (36) is represented by the following fuzzy model.

Rule i: IF $q_{1}(t)$ is $N_{l}{ }^{i}$ and $q_{2}(t)$ is $M_{l}{ }^{i}$

Then $\dot{x}(t)=\left(\mathrm{A}_{\mathrm{i}}+\Delta \mathrm{A}_{\mathrm{i}}\right) \mathrm{x}(\mathrm{t})+\mathrm{B}_{\mathrm{i}} \mathrm{u}(\mathrm{t})$,

$$
y(t)=C \mathrm{x}(\mathrm{t}) \quad \mathrm{i}=1,2, \ldots, 4
$$

Referring to (2) the fuzzy plant model given by:

$$
\begin{aligned}
\dot{x}(t) & =\sum_{i=1}^{4} \mu_{i}\left[\left(\mathrm{~A}_{\mathrm{i}}+\Delta \mathrm{A}_{\mathrm{i}}\right) \mathrm{x}(\mathrm{t})+B_{i} \mathrm{u}(\mathrm{t})\right] \\
y(t) & =\sum_{\mathrm{i}=1}^{4} \mu_{i}\left[C_{i} \mathrm{x}(\mathrm{t})+\mathrm{E}_{\mathrm{i}} \mathrm{f}(\mathrm{t})\right]
\end{aligned}
$$

where $\mathrm{x}(t) \in \kappa^{2 \mathrm{x} 1}, \mathrm{u}(t) \in \kappa^{2 \mathrm{x} 1}$ are the state vectors and the control input, respectively.

Where

$$
\begin{aligned}
& A_{1}=\left[\begin{array}{ll}
1 & 1 \\
0 & 1
\end{array}\right]\left[\begin{array}{lc}
\frac{L_{f}}{\tau L_{m d}} q_{1 \max } & \frac{L_{f}}{\tau \omega_{s} L_{m d}} q_{1 \max }\left(L_{d} i_{s d}-r_{a_{i q}} q_{1 \max }\right) \\
\frac{P_{\text {ind }}-P_{\text {load }}}{J_{s}} q_{2 \min } & -\frac{D_{s}}{J_{s}}
\end{array}\right] \\
& A_{2}=\left[\begin{array}{ll}
1 & 1 \\
0 & 1
\end{array}\right]\left[\begin{array}{lc}
\frac{L_{f}}{\tau_{L_{m d}} q_{1 \max }} & \frac{L_{f}}{\tau \omega_{s} L_{m d}} q_{1 \max }\left(L_{d} i_{s d}-r_{a_{i} q} q_{1 \max }\right) \\
\frac{P_{\text {ind }}-P_{\text {load }}}{J_{s}} q_{2 \max } & -\frac{D_{s}}{J_{s}}
\end{array}\right] \\
& A_{3}=\left[\begin{array}{ll}
1 & 1 \\
0 & 1
\end{array}\right]\left[\begin{array}{lc}
\frac{L_{f}}{\tau L_{m d}} q_{1 \min } & \frac{L_{f}}{\tau \omega_{s} L_{m d}} q_{1 \min }\left(L_{d} i_{s d}-r_{a_{i} i} q_{1 \mathrm{~min}}\right) \\
\frac{P_{\text {ind }}-P_{\text {load }}}{J_{s}} q_{2 \max } & -\frac{D_{s}}{J_{s}}
\end{array}\right] \\
& A_{4}=\left[\begin{array}{ll}
1 & 1 \\
0 & 1
\end{array}\right]\left[\begin{array}{lc}
\frac{L_{f}}{\tau_{L_{m d}}} q_{1 \min } & \frac{L_{f}}{\tau \omega_{s} L_{m d}} q_{1 \min }\left(L_{d} i_{s d}-r_{a_{i s q}} q_{1 \min }\right) \\
\frac{P_{\text {ind }}-P_{\text {load }}}{J_{s}} q_{2 \min } & -\frac{D_{s}}{J_{s}}
\end{array}\right] \\
& B_{1}=B_{2}=\left[\begin{array}{cc}
1 & -\frac{V_{c}}{J_{s}} q_{1 \max } \\
0 & -\frac{V_{c}}{J_{s}} q_{1 \max }
\end{array}\right], B_{3}=B_{4}=\left[\begin{array}{cc}
1 & -\frac{V_{c}}{J_{s}} q_{1 \min } \\
0 & -\frac{V_{c}}{J_{s}} q_{1 \min }
\end{array}\right] \\
& E=\left[\begin{array}{cc}
10 & 1 \\
0.1 & 0.01
\end{array}\right]
\end{aligned}
$$

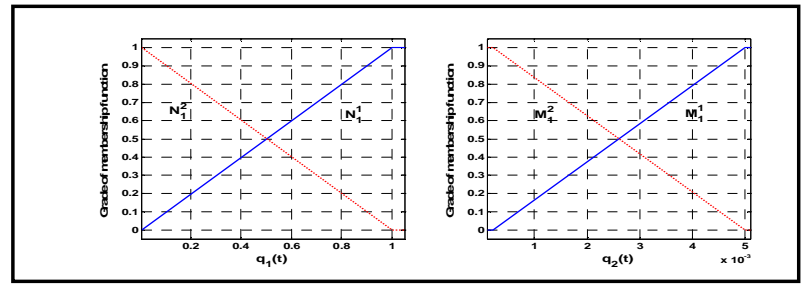

Fig.3: Membership functions of state variables

We consider respectively two sensor faults: bus voltage and generator speed sensors which are modeled as follow:

$f_{1}(t)=\left\{\begin{array}{l}0 t<14.5 \mathrm{sec} \\ 6 \sin (\pi t) t \geq 14.5 \mathrm{sec}\end{array}, \mathrm{f}_{2}(\mathrm{t})= \begin{cases}0 & \mathrm{t}<14.5 \mathrm{sec} \\ 1 & \mathrm{t} \geq 14.5 \mathrm{sec}\end{cases}\right.$

\section{Simulation studies}

The simulations are performed on a simulation model of hybrid wind-diesel storage system (36). The wind speed is considered random variation. Fig. 4 shows the sensor faults and their estimations based on (38). Fig. 5 shows the observation errors. The error between the reference state and the nonlinear systems states are shown in Fig. 6. 


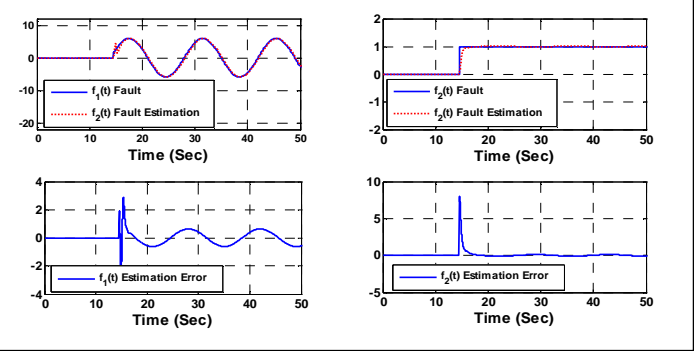

Fig. 4: Bus voltage sensor fault and its estimate and Generator speed sensor fault and its estimate

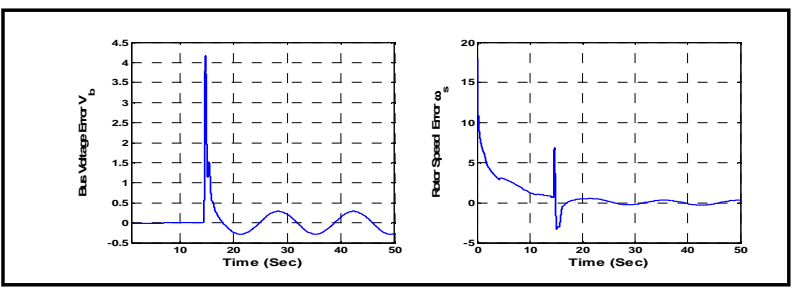

Fig.5: Estimation Error of bus voltage and generator speed

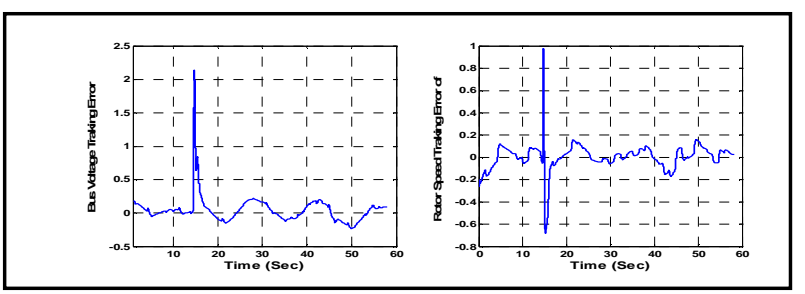

Fig.6: Error between reference and system state of bus voltage and of generator speed variables

From the simulation results it can be seen that the Fuzzy Fault Tolerant Control law compensates the bounded sensor faults. Comparing the simulation results of the proposed algorithm, with that given in the previous algorithms, it can be seen that the proposed controller can control the plant well over a wide range of sensor faults compared with [4],[5].

\section{Conclusion}

This paper is dedicated to the design of a fuzzy fault tolerant control law for nonlinear TS systems. A reference model is used and the Proposed FFTC is then designed for guaranteeing the convergence of the states of the system to the states of a reference model even if bounded sensor faults occur under the conditions that the state variables are unavailable for measurements. Some sufficient conditions for robust stabilization of the TS fuzzy model are formulated in the LMIs format. A simulation on WECS has been given to show the design procedure and the merits of the proposed fuzzy fault tolerant controller. In future works will be interesting to develop the FFTC law by taking into account parameter uncertainties and external disturbance.

\section{References}

[1] K. Tanaka, M. Sugeno, Stability analysis and design of fuzzy control systems, Fuzzy Sets and Systems, vol.45, pages 135-156, 1992.

[2] H.O. Wang, K. Tanaka, M.F. Grifn, An approach to fuzzy control of nonlinear systems: stability and de- sign issues, IEEE Trans. Fuzzy Systems, vol.4, pages 14-23, 1996.

[3] K. Tanaka, T. Ikeda, H.O. Wang, Fuzzy control system design via LMIs, Proc. American Contr. Conf., vol. 5, pages 2873-2877, 1997.

[4] A. Khedher, K. Ben Othman, D. Maquin, and M. Benrejeb , "Design of an adaptive faults tolerant control:case of sensor faults," WSEAS Transactions on Systems, vol.9, no.7, pages 794-803, 2010.

[5] Y. Wang, D. Zhou, S. Joe Qin, and H. Wang, “Active Fault-Tolerant Control for a Class of Nonlinear systems with Sensor faults," International Journal of Control, Automation, and System, vol.6, no. 3, pages 339-350,2008.

[6] X. Wei, M. Verhaegen and T. van Engelen, "Sensor fault detection and isolation for wind turbines based on subspace identification and Kalman filter techniques ", Int. J. Adapt. Control Signal Process, vol. 24, pages $687-707,2010$

[7] X. Wei, M. Verhaegen, and T. van den Engelen, “ Sensor fault diagnosis of wind turbines for fault tolerant," In Proceedings of the 17th World Congress The International Federation of Automatic Control, pages 3222-3227, Seoul, South Korea, July 2008, IFAC.

[8] C. Yong-Qi , "Design and application of fault observer for variable speed wind turbine system," Computer Engineering and Applications, vol. 45, no. 14, pages 223-227, 2009.

[9] M. Witczak, L. Dziekan, V. Puig, and J. Korbicz, "Design of a fault-tolerant control scheme for Takagi- Sugeno Systems," in 16th Mediterranean Conference on Control and Automation, Ajaccio, France, pages 280-285, 2008.

[10] K. Zhang, B. Jiang, and P. Shi, "A New Approach to Observer-Based Fault-Tolerant Controller Design for Takagi-Sugeno Fuzzy Systems with State Delay," Circuits Syst Signal Process , vol. 28, pages 679-697, 2009.

[11] M. Xiao-Jun, S. Zeng-Qi, and H. Yan-Yan ,"Analysis and Design of Fuzzy Controller and Fuzzy Observer”, IEEE Trans on Fuzzy Systems, vol. 6, no.1, pages 41-51, 1998.

[12] L. Xie, “ Output Feedback Hळ Control of Systems With Parameter Uncertainties," international journal of control, vol.63, no.4, pages 741-750, 1996.

[13] E. Kamal, M. Koutb, and A. A. Sobaih, and Belal Abozalam, “ An Intelligent Maximum Power Extraction Algorithm for Hybrid Wind-DieselStorage System," International Journal of Electrical Power \& Energy Systems, vol. 32, no.3, pages 170$177,2010$.

[14] R. B. Chedid, S.H. Karaki, and C. ElChamali," Adaptive Fuzzy Control for Wind Diesel Weak Power Systems", Transactions on Energy Conversion, vol. 15, no. 1 , pages 71-78, 2000. 